\title{
Discussion on Penetration of Traditional Music in Community Culture Construction
}

\author{
Zhicheng Li \\ Music College, Hubei Normal University, Huangshi Hubei, 435002, China
}

Keywords: Traditional music, Community culture construction, Penetration, Exploration

\begin{abstract}
The communication with western music has been more frequent in recent years under the background of wide promotion of music art. However, traditional music is not widely applied and has been forgotten by many people. In the current stage, most regions in China have implemented the construction of community culture, thus creating opportunities for the promotion of traditional music to a certain extent. The penetration of traditional music in community culture construction can not only provide community culture with a stronger sense of history and art, but also promote traditional Chinese culture positively. On this basis, it meets spiritual pursuit of people, creates a good communication atmosphere and makes people establish correct outlook on life and value and then lays a solid foundation for the construction of harmonious socialist society. This paper analyzes the important practical significance of community culture construction and problems existing in the penetration of traditional music in community culture construction and finally puts forward a specific approach for effective penetration of traditional music into community culture construction so as to promote smooth implementation of community culture construction positively.
\end{abstract}

\section{Introduction}

Under the background of rapid development of social economy in China, the quality of life and living standard of people have improved obviously. Therefore, people start to pay attention to the quality of their spiritual life while pursuing for high-quality material life. Therefore, the important role of community culture construction gradually stands out. The construction of community culture can promote the construction of spiritual civilization in China positively and play an important role in the construction process of harmonious socialist society. Effective penetration of traditional music in the construction process of community culture will achieve an ideal effect. However, traditional music is severely neglected by people and community culture construction has a bottleneck in the current stage. Therefore, it is required to understand the important role of traditional music and community culture correctly, take necessary measures for problems existing in community culture construction so as to penetrate traditional music into community culture construction more effectively and unify and integrate them, and promote traditional music based on the improvement of community culture construction.

\section{Traditional music and community culture}

Traditional Chinese music has certain national features, the specific manifestation of which is musical form with inherent national form created by laboring people with inherent methods and forms. Traditional music includes ancient and contemporary works. It has three major sources, i.e. central plains music, four-domain music and foreign music [1].

The essence of community culture is homeland culture, which is a physical form and spiritual wealth with unique features built by people within the living community and only belonging to the community. Community culture can constantly improve the sense of ownership of community residents and then better maintain the unity of community and improve the life quality of people. 


\section{Important practical significance of community culture construction}

\section{Constantly meet spiritual and cultural demands of people}

With the improvement of living standard of the masses in China, they have higher requirements for material life and pay more attention to the pursuit for spiritual life. Though the daily life and work of people are more convenient under the historical background of informatization and networking, the distance among people has increased. Constant acceleration of the pace of life increases living and working pressures of people constantly. Positive community culture construction can not only enrich the life of people, but also alleviate their living pressure and then meet their increasing spiritual and cultural demands constantly.

\section{Positively create good interpersonal atmosphere}

With the rapid development of social economy, social competition becomes fiercer and the time for work and study occupies a large proportion. Therefore, people lack sufficient time for communication with people around them. Finally, they become more disconnected with each other and then have more problems. Therefore, the implementation of community culture construction has important practical significance. It can not only gather the masses better, but also shorten their distance, make their communication more natural and smooth and then create a good interpersonal atmosphere.

\section{Make people set up good thoughts}

Positive implementation of community culture construction can not only meet spiritual and cultural demands of people, but also have certain educational functions [2].The main reason is that community culture can effectively combine traditional national culture and modern features, cultivate the taste of people in joyful atmosphere through various cultural activities and help them set up correct thoughts.

\section{Status of community culture construction}

First, the infrastructure of community culture is backward. According to the result of actual survey, about $70 \%$ streets have built cultural station and about $46 \%$ neighborhood committees have built community cultural activity room. However, internal infrastructure of community cultural site is insufficient, thus hindering further development of community culture to a certain extent.

Second, community residents have weak awareness of participating in cultural construction. Residents are subjects carrying out activities in the construction process of community culture as well as final beneficiaries of community culture construction. However, according to the analysis on the construction of community culture in China, residents have a weak awareness of participating in cultural construction. Such phenomenon is very frequent. There are several reasons: first, the current fast-paced life makes people have inadequate time for attending community activities; second, there is a great gap between community cultural activities actually implemented and those imagined by residents. Therefore, most residents are unwilling to attend community activities.

Third, professional talents are lacking in community culture construction. To improve the quality of community culture construction, it is most important to have high-quality professional talents, which is a vital factor [3].Major objects in community cultural activities are community residents. With the rapid development of cities and increased degree of opening, the degree of heterogenization of community residents is relatively high, thus causing higher and higher requirements for community culture construction. It is more expected to manifest features of diversification of community culture. However, most staffs of community culture construction are the aged retired or part-time staffs in the current stage, who have relatively backward thoughts and lack high academic qualification. Therefore, they will not put excessive energies and practice to community culture planning or implement diversified community cultural activities positively. In addition, staffs of community culture construction in the current stage have not received professional education and 
training. Most of them carry out community activities according to personal willingness or thoughts. Therefore, it is very difficult to give full play to community culture construction.

\section{Analysis on problems of penetration of traditional music into community culture construction}

\section{They haven't been actually integrated and the penetration only stays on the surface.}

Currently, traditional music has not been deeply integrated into the daily life of community residents in the construction process of community culture. Traditional music belongs to traditional Chinese culture. However, young people in the contemporary society do not understand traditional culture a lot. Therefore, western culture has gradually penetrated under the background of global cultural integration. Most people reject traditional culture. Therefore, the existence of traditional music is inevitably neglected. In this case, community staffs only penetrate traditional culture in a simple form in order to complete their work tasks in the construction process of community culture. They fail to deeply explore profound connotations of traditional music and master the essence of music so as to unify and integrate them. Therefore, even though traditional music has been publicized positively in community culture construction, the expected effect is not realized and the inheritance and development of traditional music are not achieved, thus directly causing the lack of backbone in community culture construction.

\section{Penetration lacks purpose and regularity}

Though traditional music is only a small part in traditional Chinese culture, it has experienced certain historical periods. Its most important part is the profoundness of historical connotations, which is beyond imagination. However, connotations of traditional music have not been actually interpreted comprehensively and deeply in the current community culture construction in China. Therefore, such traditional musical form is completely neglected by community residents. As people are more and more busy in work and life and do not have sufficient time for in-depth study, traditional music might be left without anybody to care for it. The main reason for such phenomenon is that the penetration of traditional music lacks certain regularity in the construction process of community culture and only blind publicity is conducted. Therefore, it will not achieve an ideal effect.

\section{Advancement and dross of traditional music are not differentiated clearly.}

Culture belongs to mental type and have both good and bad aspects. Advanced culture can promote the progress and development of human and the society positively. On the contrary, backward culture will produce adverse influence on the development of human and the society and even cause a more serious consequence. Therefore, not all traditional culture is beneficial. The dross inevitably exists. However, the advancement and dross of traditional music are not differentiated correctly in the construction process of community culture. Therefore, draffy culture has penetrated into community culture and produced adverse influence and meanwhile caused greater difficulty in the penetration of traditional music into community culture construction.

\section{Effective penetration of traditional music into community culture construction}

\section{Absorb the essence and integrate with era}

The advancement and dross of traditional culture have been described above. Therefore, it is required to absorb the essence and eliminate the dross. Advanced and excellent traditional music should be inherited so as to enrich Chinese musical forms and integrate with the era. In the construction process of community culture, it is required to inherit the essence of traditional music, fully consider social development trend and increasing demands of people and then innovate and develop it scientifically and reasonably. However, innovation does not simply stay at the level of written and theoretical researches. As music has spirituality and belongs to vocal art, it is most important to continue singing in the inheritance of traditional music. On this basis, it is also required 
to break through the set pattern of traditional music, integrate it with community culture construction and then seek for modern music technologies and give traditional music more active era elements, thus enabling people to like traditional music and further promoting cultural development ${ }^{[5]}$.

\section{People first and guarantee the orderliness of penetration}

It is required to regard community residents as the core in the construction process of community culture and develop and innovate community culture on this basis. The penetration of traditional music in community culture construction requires certain purposiveness and regularity. It should not be conducted blindly; otherwise, it will be more chaotic. Therefore, it is most important to understand community residents' understandings and views about traditional music, conduct comprehensive market survey, arrange and analyze data obtained in detail, make judgments according to data contents and guarantee the correctness of judgment so that community residents can love traditional music. Then, it is necessary to establish a scientific and reasonable plan and realize the penetration of traditional music in community culture construction so as to allow community residents to feel the most real traditional music and constantly enrich the content of community culture.

\section{Realize the integration with scientific model}

As is known to all, traditional music is a part in traditional Chinese culture. Therefore, it is necessary to manifest it through a carrier. There must be traditional artists for performance in order to penetrate traditional music in the construction process of community culture better. Performance venue and background team are required before performance. Therefore, to realize the promotion and inheritance of traditional music, it is most critical to gain strong support from relevant educational institutions. Therefore, in order to effectively penetrate traditional music in community culture, it is necessary to build a specific site for promoting traditional music art and prepare relevant infrastructures of music art organizations. On this basis, it is also required to cooperate with different art centers, constantly expand the approach for promotion of traditional music in community culture and then set up a good image for traditional music.

\section{Conclusion}

In conclusion, according to the study on traditional music and community culture construction, the penetration of traditional music in community culture construction is not successful and continuous efforts are required. It is required to make full use of existing resources and technologies, make correct judgments and establish a publicity program meeting requirements; not only implement community culture construction work well, but also inherit excellent traditional Chinese culture and traditional music positively, guarantee advancement with the times and constantly develop new culture of traditional Chinese culture. This paper conducts a survey on traditional music and community culture, analyzes the important practical significance of community culture in national development, meanwhile discusses problems existing in community culture construction, studies the status of penetration of traditional music in community culture construction and puts forward strategies for effective penetration of traditional music in community culture construction in allusion to existing problems mentioned above. The main objective is to promote the construction of community culture positively, form excellent traditional music culture, establish harmonious socialist society better, lay a solid foundation for future spiritual and cultural development in China and promote further development of China.

\section{References}

[1] Liu Lei. Penetration of Traditional Music in Community Culture Construction. Decision and Information (Midmonth), 2015(10):75. 
[2] Guo Zhiying, Yang Xiangyong. Initial Solution for Joint Development of Community Music Culture - Study on Construction Mode of Community Music Culture in Anyang. Culture and Art: Last Third of Month, 2011(9):274-275.

[3] Liu Nannan. Relationship between Music Education and Harmonious Community Culture Construction. Journal of Hubei Correspondence University, 2015(8):190-191.

[4] Wu Suqin. Yu Gewen. Exploration on Penetration of Local Music Art in Community Culture Construction. Popular Literature, 2012(17):32-33.

[5] Fu Hui. Thinking on Community Music Culture Construction and National Music Inheritance Take Tibetan Music Culture for Example. Contemporary Literary World, 2014(5):179-183. 